\title{
Limited Learning on College Campuses
}

\author{
Richard Arum • Josipa Roksa
}

Published online: 25 March 2011

(C) Springer Science+Business Media, LLC 2011

Politicians, policymakers, and private foundations have united in recent years around achieving a common goal: college for all. As President Barack Obama pledged in his first speech to a joint session of Congress in February 2009: "We will provide the support necessary for you to complete college and meet a new goal: by 2020, America will once again have the highest proportion of college graduates in the world." At the beginning of the 21 st century, increasing and ensuring individual access to college presents itself not just as a moral imperative, but an economic necessity. As employment opportunities in manufacturing continue to grow scarcer in the United States, both individual and national global economic competitiveness requires mastery of what many commentators have termed " 21 st century skills." These skills, generally thought uniformly taught at U.S. colleges and universities, are defined as including critical thinking, complex reasoning, and written communication. But what if sending students to college did not necessarily ensure that much was learned once there? What if at the beginning of the 21 st century many colleges and universities were not focused primarily on undergraduate learning, but instead had become distracted by other institutional functions and goals?

We have systematically investigated the state of undergraduate learning in contemporary colleges and universities. Following more than 3,000 traditional-age students as they enrolled in coursework from Fall 2005 to Spring 2009,

\footnotetext{
R. Arum $(\bowtie)$

Department of Sociology, New York University,

295 Lafayette - 4th Floor,

New York, NY 10012, USA

e-mail: richard.arum@nyu.edu

J. Roksa

Department of Sociology, University of Virginia, P.O. Box 400766, 555 New Cabell Hall, Charlottesville, VA 22904, USA

e-mail: JRoksa@virginia.edu
}

across a wide range of 29 four-year colleges and universities, we found a set of conditions suggesting that something indeed is seriously amiss in U.S. higher education. In Academically Adrift: Limited Learning on College Campuses (University of Chicago Press, 2011), we have described some of these disturbing conditions and documented the extent to which many students show little if any growth over the first 2 years of college in their ability to perform tasks requiring critical thinking, complex reasoning, and written communication as measured by the Collegiate Learning Assessment (CLA). In the report Improving Undergraduate Learning: Findings and Policy Recommendations from the SSRC-CLA Longitudinal Project on which this summary is based, we extend those findings to document the rate of growth on the CLA for the full 4 years of college, academic practices associated with improved student performance, as well as differences across individuals and institutions in the level of learning. The 4 year results confirmed the broad patterns and trends based on 2 years of data analysis identified in Academically Adrift.

\section{Limited Academic Engagement and Learning Outcomes}

While higher education is expected to accomplish many tasks, existing organizational cultures and practices too often do not prioritize undergraduate learning. Given these institutional climates, it is perhaps not surprising that large numbers of college students report that they experience only limited academic demands and invest only limited effort in their academic endeavors. Our research documents that many contemporary college students enroll in courses that do not require either substantial writing or reading assignments. In a typical semester, 32\% did not take any courses with more than 40 pages of reading per week and $50 \%$ did not take a single course in which they wrote more 
than 20 pages over the course of the semester. A quarter of students experienced neither of those course requirements in a typical semester.

Moreover, on average, students in a typical semester spend only between 12 and $14 \mathrm{~h}$ per week studying (approximately $50 \%$ less time than full-time college students did a few decades ago, according to recent research by labor economists Phillip Babcock and Mindy Marks published in the Review of Economics and Statistics). Combining the hours spent studying with the hours spent in classes and labs, students spend less than one-fifth $(16 \%)$ of their time each week on academic pursuits. In addition, when studying and preparing for class, students attending four-year colleges on average spend about onethird of their time studying with peers in social settings that are not generally conducive to learning. Excluding studying with peers from our calculations, college students on average spend only between 8 and $9 \mathrm{~h}$ per week studying alone. More troubling still, 35\% of students at four-year colleges report that they spend five or fewer hours per week studying alone.

Our findings on limited collegiate academic investment and curricular demands replicate findings identified by the National Survey of Student Engagement (NSSE), which over the past decade has surveyed more than 2 million students at more than 1,000 colleges and universities. Among other results, NSSE reveals a limited amount of time students spend studying (13-14 $\mathrm{h}$ for full-time students, 9-10 h for part-time students) and meager writing requirements found in contemporary undergraduate coursework (for example, $51 \%$ of college seniors reported that they had not written a paper during the current academic year that was 20 or more pages long; even at the top $10 \%$ of schools in the NSSE study, $33 \%$ of college seniors reported that they had not written a paper of this length during their last year in college).

Considering these limited academic investments, how much are students learning in higher education? We assessed student learning using the performance task of the Collegiate Learning Assessment (CLA). The CLA aims to measure general skills-based competencies such as critical thinking, analytical reasoning, and written communication. Although CLA has multiple components, we focused on the performance task because it was administered most uniformly across institutions, had the largest completion rate, and is the state-of-the-art component of the assessment instrument. The performance task allows students $90 \mathrm{~min}$ to respond to a writing prompt that represents a "real-word" scenario in which they need to use a range of background documents (from memos and newspaper articles to reports, journal articles, and graphic representations) to solve a task or a dilemma. The testing materials, including the background documents, are accessed through a computer. For more information on the CLA, see http:// www.collegiatelearningassessment.org/.

Given the limited academic engagement shown by many students, it is not surprising that gains in student performance on the CLA are disturbingly low. We find in our study that on average, gains in critical thinking, complex reasoning, and writing skills (i.e., general collegiate skills) are either exceedingly small or empirically non-existent for a large proportion of students. Forty-five percent of students did not demonstrate any significant improvement in learning, as measured by CLA performance, during their first 2 years of college. Considering all 4 years of college, we find that $36 \%$ of students did not demonstrate any significant improvement in learning, as measured by CLA performance. On average, students improved performance on the CLA by only 0.18 standard deviations over the first 2 years of college and 0.47 standard deviations for the full 4 years of college. Students who scored at the 50th percentile of students in their entering freshman cohort would have moved up only to the 68th percentile after 4 years of college (if, when graduating college, the students retook the test with a new cohort of entering freshmen). In an extensive review of the literature presented in How College Affects Students, Ernest Pascarella and Patrick Terenzini estimated that students in the 1980s learned at twice the current rate-seniors at that time had an advantage of one standard deviation over freshmen in critical thinking.

If students' self-reports of their own academic engagement were not so limited, one might be tempted to dismiss these findings as a methodological artifact associated with a limitation of the essay-based, open-ended assessment approach used by the CLA. Related work conducted by a research team led by Charles Blaich at the Center of Inquiry in the Liberal Arts at Wabash College also puts such objections to rest. While we found that students on average gained only 0.47 standard deviations on the CLA between their fall freshman and spring senior semesters, Blaich found that students in participating colleges he studied gained only 0.44 on an alternative close-ended, multiple choice assessment indicator of critical thinking and complex reasoning (ACT's Collegiate Assessment of Academic Proficiency).

\section{Academic Factors Associated with Learning}

Although on average students are making small gains on the CLA, there is much variation across students, and our results indicate that this variation is associated with their collegiate experiences. In general, our findings suggested that educational practices associated with academic rigor improved student performance, while collegiate experiences 
associated with social engagement did not. Specifically, our results identified several measures associated with academic rigor that were conducive to improved student performance on the CLA: students who spent more hours studying alone had greater gains on the CLA; students who took courses requiring both significant reading (more than 40 pages per week) and writing (more than 20 pages over the course of the semester) had higher rates of learning; students reporting faculty with high expectations at their institutions had higher rates of learning; and students who had more advanced coursework in high school had greater subsequent gains on the CLA in college. While educational practices associated with academic rigor facilitated learning, measures associated with student social engagement did not: students who spent more hours studying with peers showed diminishing growth on the CLA; students who spent greater hours in fraternities and sororities had decreased rates of learning; and other student activities, such as working on or off campus, participating in campus clubs/organizations, and volunteering, were not related to learning.

The extent to which our findings highlight the importance of academic rigor over social engagement for learning should serve as a cautionary signal to colleges that have emphasized the latter in efforts to increase student retention in higher education. These results, however, do not suggest that all forms of group-learning experiences should be abandoned. Group learning in specifically structured contexts, such as within learning communities or particular majors, may facilitate students' mastery of course material and development of general skills. Further research is needed to assess how specific types of group-centered activities are related to objective measures of student learning.

\section{Variation Across Institutions and Individuals}

While the average trends in our data indicate that too many students are embedded in institutions that place very limited academic demands on them and that limited learning occurs for all too many students during college, there is notable variation across students as well as across institutions. In our study, we found many high-performing students from all socio-economic backgrounds and racial/ethnic groups, as well as students with different levels of academic preparation, who improved their performance on the CLA at impressive rates while enrolled in college. In virtually every college examined we found students who were devoting themselves to their studies and learning at rates substantially above the average.

There is Notable Variation in Experiences and Outcomes Across Institutions Students attending certain institutions have more beneficial college experiences (in terms of reading/writing requirements, hours studying, and high faculty expectations) and demonstrate significantly higher gains in critical thinking, complex reasoning, and writing skills over time, even after we control for students' individual characteristics.

Colleges and universities make a difference in improving student performance. Over 4 years of college, we find that $23 \%$ of variation in CLA performance occurs across institutions. In particular, we find that institutional differences associated with student selectivity are related to increased growth in CLA performance over 4 years of college. Selectivity of entering freshmen is a measure that likely taps multiple sources of institutional variation, including differences in peer orientations and student behaviors with respect to academic endeavors, variation in curricular demands, as well as variation in faculty expectations.

There is More Variation Within Institutions than Across Institutions Although institutional selectivity is related to students' experiences and growth in CLA, high- and lowperforming students can be found at each institution and within each level of selectivity. Students demonstrating substantial learning (e.g., the top $10 \%$ of the CLA growth distribution) are found at each institution. We also find persisting or growing differences across groups in student performance in higher education. Black-white gaps in student test score performance, for example, increase in magnitude over 4 years of college. In addition, we find notable variation in academic experiences and outcomes across fields of study. Variation by field of study may reflect a range of different factors, including differences in curriculum as well as differences in academic aptitude and orientations of students who have chosen particular majors. While appreciating the diverse causes of differences by field of study, we note that students majoring in traditional liberal-arts fields, including social science, humanities, natural science, and mathematics, demonstrated significantly higher gains in critical thinking, complex reasoning, and writing skills over time than students in business majors. Students majoring in business, education, social work, and communications had the lowest measurable gains. Greater gains in liberal-arts fields are at least in part related to faculty requiring higher levels of reading and writing and students spending more time studying in these programs. Reported findings do not preclude the possibility that students in other fields are developing subject-specific or occupationally relevant skills that are not assessed by the CLA.

Differences in student outcomes both across and within higher education institutions highlight the extent to which colleges seeking to improve student learning can gain as 
many insights by looking within for institutional strengths and weaknesses as looking outside to exemplary institutions. NSSE's work on Project DEEP (Documenting Effective Educational Practice) and the efforts of the Association of American Colleges and Universities (AAC\&U) to develop principles of effective practices, such as those outlined in General Education \& Liberal Learning: Principles of Effective Practice, provide at least two recent examples of on-going efforts to improve undergraduate academic experiences and outcomes.

\section{Implications}

In recent years, discourse around higher education has increasingly focused on improving college access, retention, and completion. Our research, however, highlights the need for policymakers and practitioners to focus as much attention on improving student learning as has been demonstrated in recent years toward these other laudatory goals. There are no simple solutions to the problem of limited learning on college campuses. Improving learning outcomes in undergraduate education will require the commitment and dedication of a diverse set of individuals and institutions. One cannot mandate learning through the imposition of increased regulation; rather, for change to occur, various entities and actors will have to demonstrate in their behaviors and actions a deep commitment to these goals and a willingness to take personal and institutional responsibility for their successful achievement.

Before identifying policies and practices that we believe will lead to improvement in student learning, we explicitly note here our reservations to one proposed remedy that has received much attention. In our estimation externally imposed accountability systems would be counterproductive. Our findings are disturbing enough that many wellintentioned legislators might be easily tempted to call for the imposition of a federally mandated accountability system for higher education institutions, similar to those recently introduced in K-12 education. While such sentiments would be understandable given our findings on the state of undergraduate learning, we believe that such efforts at this time would be counterproductive. Our current ability to measure accurately diverse forms of students' general and subject-specific performance is still in the early stages of development. While we support the promotion of increased personal and institutional responsibility to address this issue, the imposition of federally mandated regulatory schemas would likely have unintended negative consequences that would far outweigh any demonstrated improvements. Efforts to mandate the use of specific measures for accountability purposes (as opposed to promoting their use for research and internal formative assessment tied to improving instruction) would likely be counterproductive at this time.

In the context of the changing economic and global context facing contemporary college graduates, and our commitment to the development of an educated citizenry capable of contributing constructively to a democratic society, we offer several recommendations as next steps for improving collegiate learning.

\section{K-12 System Improvement}

- Improved elementary- and secondary-school student preparation. Given that students who are better prepared upon matriculation into college demonstrate increased learning and better performance in higher education, there must be continued concerted efforts to improve academic preparation. Current endeavors to increase achievement in K-12 and align postsecondary curricula with higher education deserve careful attention and need to be supplemented with efforts to help students develop mature values and behaviors conducive to learning.

\section{Higher Education Institutional Recommendations}

- Strong leadership in higher education to foster an institution-wide culture of learning. Institutional leaders and administrators need to take responsibility for modifying existing internal institutional incentives and practices to develop - and articulate a commitment to embracing - organizational cultures that prioritize undergraduate learning and student assessment. College and university trustees, regents, and overseers must work to ensure that institutional leaders and administrators prioritize undergraduate learning as an organizational goal. Institutional leaders and administrators should be held accountable by these existing governance mechanisms, which should require internal reporting on measurable student learning outcomes, expenditures devoted to instructional purposes, and institutional activities devoted to improving instruction.

- Enhanced curriculum and instruction associated with academic rigor. More rigorous, appropriately demanding course requirements and standards must be put in place to ensure the development of critical thinking, complex reasoning, and written communication skills (i.e., increased academic assignments requiring greater student effort, adequate student reading and writing, and high expectations by faculty). Moreover, if active/ collaborative learning approaches outside the classroom 
are adopted as instructional models, these models must be specifically structured and carefully assessed to ensure that adequate academic development is occurring.

- Faculty must take collective and individual responsibility for ensuring that coursework offered at their institutions is both rigorous and demanding. Faculty should have high standards and expectations for their students and should be adequately trained and supported by their institutions to serve as effective instructors.

- Students must take responsibility for embracing the academic opportunities they have been afforded. Colleges and universities must promote organizational cultures that encourage and require students to demonstrate serious commitment to academic endeavors and to take responsibility for devoting sufficient time to their studies.

- Increased measurement of student learning. Colleges and universities should consistently collect diverse, comprehensive sources of evaluation and assessment data to improve instruction and student learning on an ongoing basis. Given the great variation in student performance within institutions in our study, all schools would benefit from developing internal organizational mechanisms to identify the strengths and weaknesses of their respective curricular programs in order to engage in ongoing instructional improvement efforts that are informed by assessment data. Institutions can learn from and build on the efforts of colleges and universities currently engaging in assessment of learning for institutional improvement, such as those participating in the Voluntary System of Accountability or the New England Consortium on Assessment and Student Learning.

\section{System Level Actions}

- Reallocation of government resources to improve undergraduate learning. While public investment in research is a worthy end, federal and state government grant programs tied to improvement of undergraduate learning and its assessment on both institutional and individual levels would encourage the development of policies and practices to enhance undergraduate educational outcomes.

- Enhanced research infrastructure for measuring and understanding student learning in higher education. In addition to the recommendations for practitioners and policymakers identified above, our research identifies the importance of embedding longitudinal measurement of collegiate learning outcomes in future federally organized national probability studies. Such measures would greatly enhance the available research infrastructure to allow future social science researchers to better identify determinants of collegiate learning. Moreover, limited place, randomized field trials of promising curricular and instructional models would generate increased knowledge of effective programmatic interventions to guide policy and practice.

Acknowledgement Richard Arum and Josipa Roksa are authors of Academically Adrift: Limited Learning on College Campuses (University of Chicago Press). This manuscript is drawn and modified from the report Improving Undergraduate Learning: Findings and Policy Recommendations from the SSRC-CLA Longitudinal Project (New York: Social Science Research Council, 2011). Financial support for the research was provided by The Lumina Foundation for Education, the Ford Foundation, the Carnegie Corporation of New York, and the Teagle Foundation, as well as a 2007-08 Fulbright New Century Scholar "Higher Education in the 21st Century: Access and Equity" award. We are grateful to the Council for Aid to Education for technical collaboration in data collection.

\section{Further Reading}

Arum, R., \& Roksa, J. 2011. Academically adrift: Limited learning on college campuses. Chicago: University of Chicago Press.

Arum, R., Roksa, J., \& Cho, E. 2011. Improving undergraduate learning: Findings and policy recommendations from the SSRC-CLA longitudinal project. New York: Social Science Research Council.

Babcock, P., \& Marks, M. Forthcoming. The falling time cost of college: Evidence from half a century of time use data. Review of Economics and Statistics.

National Survey of Student Engagement (NSSE). 2007. Experiences that matter: Enhancing student learning and success. Bloomington, IN: Center for Postsecondary Research, Indiana University Bloomington.

Pascarella, E. T., \& Terenzini, P. T. 2005. How college affects students: A third decade of research. San Francisco: Jossey-Bass.

Wabash National Study of Liberal Arts Education, Center of Inquiry in the Liberal Arts, http://www.liberalarts.wabash.edu/.

Richard Arum is professor in the Department of Sociology with a joint appointment in the Steinhardt School of Education at New York University. He also directs the Education Research Program of the Social Science Research Council and is author of Judging School Discipline: The Crisis of Moral Authority in American Schools.

Josipa Roksa is assistant professor of sociology at the University of Virginia. She is also a Faculty Affiliate at the Center for Advanced Study of Teaching and Learning at UVA, and a Fellow of the National Forum on the Future of Liberal Education. 